\title{
Development and Assessment of Effects of De-Stress Training Program on Stress of Mothers With Mentally Disabled crossuark Children
}

\author{
Leila Charmforoush Jalali', Saeed Hasanzadeh ${ }^{2 *}$, Mehdi Davaee ${ }^{3}$, Gholamali Afrooz ${ }^{2}$ \\ 1. Department of Exceptional Children Psychology, Faculty of Humanities and Social Sciences, Science \& Research Branch, Islamic Azad University, \\ Tehran, Iran. \\ 2. Department of Psychology \& Education of Exceptional Children, Faculty of Psychology and Education, University of Tehran, Tehran, Iran. \\ 3. Department of Training Sciences, Faculty of Psychology and Social Sciences, Central Tehran Branch, Islamic Azad University, Tehran, Iran.
}

\begin{tabular}{|c|c|}
\hline $\begin{array}{l}\text { Use your device toscan } \\
\text { and read the article online }\end{array}$ & Citation: Charmforoush Jalali L, Hasanzadeh S, Davaee M, Afrooz Gh. Development and Assessment of Effects of De-Stress \\
\hline 口ifip & $\begin{array}{l}\text { Training Program on Stress of Mothers With Mentally Disabled Children. Iranian Rehabilitation Journal. 2016; 14(4):223-228. } \\
\text { https://doi.org/10.18869/nrip.irj.14.4.223 }\end{array}$ \\
\hline 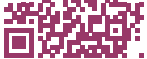 & doi : : https://doi.org/10.18869/nrip.irj.14.4.223 \\
\hline
\end{tabular}

Article info:

Received: 22 Jun. 2016

Accepted: 04 Nov. 2016

Keywords:

Mentally disabled children, Parenting stress, De-stress training program

\begin{abstract}
Objectives: Any form of disability is considered a critical factor having significant effects on a family. Stress is the main result of such effects on parents. According to the classical procedure, the mothers play a major role as child caregiver, so they experience more stress than other members of the family. The goal of this study was to develop and assess the role of the de-stress training program in decreasing the stress of mothers of mentally disabled children.
\end{abstract}

Methods: This study was a semi-experimental research with follow-up. The study sample included 20 mothers of children with mental disabled who live in Tehran. The parental stress scale was used for measuring mother's stress. Data was analyzed by univariate analysis of covariance.

Results: The data presented a significant difference between the control and experiment groups. Also, the results did not show a significant difference between pre-test and follow-up, indicating a persistent effect of the training.

Discussion: De-stress training program was found to significantly decrease the stress of mothers of mentally disabled children.

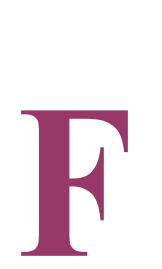

\section{Introduction}

amilies with child disability encounter many challenges that require reorganization. The first steps toward acceptance and growing a child with disability and necessities of special caregiver have different effects on the family. Most of the parents share positive experience of bringing up their children, except the parents of mentally- or physically-disabled children. The birth of a child with a disability is unexpected for parents, and it has notable consequences. The stages of grief for parents of children with special needs are: 1 . Shock, 2. Denial, 3. Guilt, 4. Anger, 5. Depression, 6. Frustration, 7. Anxiety and 8. Acceptance [1].

The birth of a child with mental disability is not out of this role. Children with mental disability have spe- 
cial characteristics, such as under average of intelligence quotient, limitation of memory, word storage, abstract thinking, visual and auditory deficit and immovability. These signs indicated children with Down syndrome, micro cephalic, and macro cephalic difficulties [2].

Some researchers have addressed the concept of social stigma [3]. Social stigma is the extreme disapproval of (or discontent with) a person or group on the ground of social characteristics that are perceived and serve to distinguish them from other members of society. Stigma may then be affixed to such a person who differs from their cultural norms by the greater society. Experiences and others who have direct relations with this person can be affected by stigma. Relatives may internalize the received stigma that may affect their lives. More than the responsibility of bringing up a child with a disability, the mother's perception of internalized stigma increases the stress of the child [4].

Needs of such children often scares the parents. Hence, they need to deal with them in patience. It leads to forgetting their self, inattention to other children, and incompatibility [5]. Moreover, the birth of a mentally-disabled child can often result in difficulty in marriage and relations with relatives, siblings, and neighbors [6].

The birth of a child with disability arouses a wide range of sensitive responses in parents. It is a critical subject for some parents as it needs mental regulation. For others, it is a regretful event, and initial response to such event is the affective collapse [7]. The birth of a child with mental disability can have deep effects on the whole family (both parents and children) and extended family (grandfather and grandmother). It is a common experience among all members of a family that affects all aspects of family functions [8]. Stress is the consequence of having a child with mental disability when the demands are more than abilities [9].

Parental stress can be perceived as a challenge between the parental duties and existing capacity of parents [10]. Stress has various effects on life. It impairs the social, psychological and physical functions. Parental roles will get limited by stress, and it may increase the chronic diseases like blood pressure and heart diseases [11]. Some researchers estimate the parental $[12,13]$. Finally, most of the studies show that stress correlates with a decrease in mental health [14], low life satisfaction, [15] behavioral problems, [16] and possess challenges in economic wellbeing [17].

Coping with stress is more attended by the psychologists. Some of the therapists believe that changing cognitive behavior leads to a decrease in stress [18]. Psycholo- gists believe that evaluation of an event is a useful coping skill against stress. Evaluation of an event or cognition is different from one to another, and people's behavior is based on these cognitive abilities [19].

Studies on stress management started from 1930 when Hill presented his ABC-X model about family stress management. This model is designed for coping stress in a family as a whole and a family with mentally disabled child as specific [19].

According to the importance of family in bringing up children with mental disability, the management of parental stress s considered necessary. Hence, the goal of this study is to design and assess the effects of familybased stress management program on the stress of mothers of mentally disabled children.

\section{Methods}

This study was an applicable research. It was a semiexperimental method with follow-up. The study population included all mothers who have children with mental disability in Tehran-Iran. The study sample included 20 subjects who were selected randomly and placed in experimental and control groups.

The inclusion criteria for each subject were as follows: diagnosis of mental disability based on documents, less than 16 years of age, and mothers who at least finished schools. After selecting the sample group and performing the pretest, the experimental group received de-stress training program. This program was designed based on the stress inoculation training of Donald Meichenbaum (reference). Also, the Jacobson' progressive relaxation training was used. Jacobson suggested that anxiety leads to tension in muscles, and removal of tension led to the removal of anxiety [20].

All subjects performed the parental stress scale of Berry \& Jones (1995). It provides a measure that considers the positive aspects of parenting as well as the negative stressful aspects. It is an 18 -item self-report scale, and it should be noted that parents either agree or disagree with the asked items related to their child or children. Seven expressions, namely 1, 2, 5, 6, 7, 17 and 18, were scored reversely, and the rest were directly scored. In this test, the minimum number was 18 and maximum was 90. Berry \& Jones (1995) have reported the test validity and test-post test validity to be 0.83 and 0.80 , respectively. The scale primer verification for assessing validity was performed on 23 mothers that was later translated into Farsi. The obtained test-post test validity was equal to 0.78 , with a one-week interval [21]. Brief description of each session is presented in Table 1. 
Table 1. Description of each session.

\begin{tabular}{|c|c|}
\hline Sessions & Brief Description of Each Session \\
\hline 1,2 & Introducing, presenting goals, method and performance \\
\hline 3 & Jacobson's progressive relaxation training, analysis of environment, response to questions, homework \\
\hline 4 & Parenting skills training, Jacobson's progressive relaxation training, homework \\
\hline 5 & $\begin{array}{c}\text { Self-monitoring, information about mental disability, anger management, Jacobson's progressive relaxation training, } \\
\text { homework }\end{array}$ \\
\hline 6 & $\begin{array}{c}\text { Anger management, facilitation communication, response to questions, Jacobson's progressive relaxation training, } \\
\text { homework }\end{array}$ \\
\hline 7 & $\begin{array}{l}\text { Parenting skills training with focus on healthy environment, facilitating communication of sibling, Jacobson's progres- } \\
\text { sive relaxation training, homework }\end{array}$ \\
\hline 8 & Finding false thoughts, following the rehabilitation periods, Jacobson's progressive relaxation training, homework \\
\hline 9 & $\begin{array}{l}\text { Recognizing negative thoughts and replacing them with positive thoughts, having real expectations, considering the } \\
\text { feedback and demands of parents and children, Jacobson's progressive relaxation training, homework }\end{array}$ \\
\hline 10 & $\begin{array}{l}\text { Self-caring, focus on now, reasonable demands (self and others), Jacobson's progressive relaxation training, home- } \\
\text { work }\end{array}$ \\
\hline 11 & $\begin{array}{c}\text { Self-talking technique, considering anger management, assertiveness, considering needs of children, Jacobson's } \\
\text { progressive relaxation training, homework }\end{array}$ \\
\hline 12 & $\begin{array}{l}\text { Considering attention to self, problem-solving skills, considering mothers reaction to stress, Jacobson's progressive } \\
\text { relaxation training, homework }\end{array}$ \\
\hline 13 & Review of last session, response to questions, considering feedback to trainings \\
\hline 14 & Post-test \\
\hline 15 & Follow-up \\
\hline
\end{tabular}

Iranian Rehabilitation Journal

Stress management training program

Post-test is performed in the $14^{\text {th }}$ session and after 1 month's re sult follow-up. The obtained data were analyzed by descriptive and inferential statistics.

\section{Results}

The descriptive characteristics of experimental and control groups are presented in Table 2. According to the obtained differences between groups, the univariate analysis of covariance was used for demonstrating the significant differences. According to Table 3, the experimental and control groups showed significant differences. After covariance analysis and omission of initial differences, there were significant differences between both the groups $(\mathrm{F}=11.03 \mathrm{P}<0.01)$.

Based on the results, the mean of maternal stress decreased in post-test. Therefore, it can be said that fam- ily-based stress management program significantly decrease the mother's stress. As shown in Table 4, there is no significant difference between post-test and followup points of maternal stress. It means that effectiveness of family based stress management program on decreasing of stress seems to be persistent.

\section{Discussion}

The study results showed that de-stress training program has significant effects on stress. One reason for the effectiveness of this program was the active participation of mothers in all sessions. In other words, the mothers were not just listener; they had time to describe their feelings and thoughts. Therefore, this led to empathy and released emotions. Moreover, the mothers also shared their experience together, and it helped them in solving problems and managing their stress level.

Table 2. Descriptive characteristics of dependent variables in experimental and control groups.

\begin{tabular}{|c|c|c|c|c|c|c|c|c|}
\hline \multirow[b]{3}{*}{ Variables } & \multicolumn{4}{|c|}{ Experimental Group } & \multicolumn{4}{|c|}{ Control Group } \\
\hline & \multicolumn{2}{|c|}{ Pre-test } & \multicolumn{2}{|c|}{ Post-test } & \multicolumn{2}{|c|}{ Pre-test } & \multicolumn{2}{|c|}{ Post- test } \\
\hline & $\mathrm{M}$ & SD & $\mathrm{M}$ & SD & $\mathrm{M}$ & SD & $\mathrm{M}$ & SD \\
\hline Maternal stress & 46.90 & 7.19 & 35.10 & 7.65 & 47.90 & 10.05 & 47.60 & 9.80 \\
\hline
\end{tabular}


Table 3. Brief results of univariate analysis of covariance.

\begin{tabular}{ccccccc}
\hline Variable & SS & df & MS & F & Sig. & nP2 \\
\hline Pre-test & 1288.95 & 1 & 122.95 & 214.09 & 0.01 & 0.93 \\
Group & 662.45 & 1 & 662.45 & 110.03 & 0.01 & 0.87 \\
Error & 102.35 & 17 & 6.02 & & & \\
\hline
\end{tabular}

Iranian Rehabilitation Journal

Table 4. Descriptive characteristics and dependent $\mathrm{T}$ test.

\begin{tabular}{|c|c|c|c|c|c|c|c|c|}
\hline \multirow[t]{2}{*}{ Group } & \multirow[b]{2}{*}{ Variable } & \multicolumn{2}{|c|}{ Post-test } & \multicolumn{2}{|c|}{ Follow up } & \multicolumn{3}{|c|}{ Dependent T test } \\
\hline & & M & SD & M & SD & $\mathbf{t}$ & df & Sig. \\
\hline Experimental & Maternal stress & 35.10 & 7.65 & 43.50 & 12.89 & 0.55 & 9 & 0.59 \\
\hline control & Maternal stress & 47.60 & 9.80 & 52.60 & 10.08 & -1.21 & 9 & 0.22 \\
\hline
\end{tabular}

Iranian Rehabilitation Journal

An existing problem for the mothers is the differences between normal and mentally disabled children. Usually, mothers with favoritism toward mental disabled child increase the family challenges. In this program, the mothers were trained for undertaking strategies for coping up with such family challenges. Also, the necessary information about children with mental disability has been presented in these sessions.

In this program, the stress inoculation training designed by Meichenbaum was used. The method did not focus just on a special technique, individual differences were more attended [22, 20]. Attention to critical needs of mothers with mentally disabled child guided the sessions toward clear and real needs. Overall, introducing the concept of mental disability to mothers, sharing experiences, training strategies for coping stress and all other factors led to controlling stress and coping with the associated problem.

The results of the study showed that stress management program has significant effects on decreasing stress. It accommodates with the previous field-related studies stating the effectiveness of coping strategies training in decreasing psychological signs of mothers with down child [23], effectiveness of stress management with cognitive- behavior therapy in decreasing anxiety and depression of parents with mentally disabled children [24], effectiveness of positive therapy in decreasing anxiety [25], effectiveness of primary intervention in improving social supports [26], effectiveness of coping skills training in maternal stress [27], effectiveness in coping skills training and stress management on decreasing anxiety and depression of mothers with disabled child [28].
The results of this study are not in line with the findings of Kaveh et al [29]. They used resiliency program against stress and showed that this program was not effective in decreasing stress. They suggested that their inconsistent finding will be referred to using general questions in the questionnaire[29]. The content of the stress management program used in this study was according to other methods like cognitive- behavioral [23, 24, 27] and progressive relaxation therapy $[23,27]$.

Anger management is a factor that is focused on stress management. This factor in other programs was considered important [23]. It seemed that using cognitive-behavioral therapy, relaxation and anger management were very effective in decreasing stress. This study approves the last findings. The present study also showed that effectiveness of the program was persistent, which was in line with the finding of other studies [30].

It can be concluded that de-stress training program is significantly effective in decreasing maternal stress. It features the necessities of regular and persistent training to mothers. On the other hand, empowerment of the family with mentally disabled children should be regarded beside other rehabilitation strategies.

\section{Acknowledgments}

This research did not receive any specific grant from funding agencies in the public, commercial, or not-for-profit sectors.

\section{Conflict of Interest}

The authors declared no conflict of interests. 


\section{References}

[1] Heward WL. Exceptional Children. $6^{\text {th }}$ ed. New Jersey: Prentice Hall Inc; 2000

[2] Afrooz GA. Psychological and rehabilitation of slow pace Children. Tehran: Nashr-e Daneshgahi; 2014

[3] Goffman E. Estigma; Nots on the management of spoiled identity. New York: Prentiss-Hall; 1963

[4] Green SE. We're tired, not sad; Benefits and burders of mothering a child with a disability. Social Science and Medicine. 2007; 64(1):150-63. doi: 10.1016/j.socscimed.2006.08.025

[5] Motamedin M, Sohrabi F, Fathi-Azar S, Maleki S. [The comparison of mental health, marital satisfaction and assertive parents of students with mental retardation and normal student in West Azerbaijan Unit (Persian)]. Journal of Knowledge and Research. 2009; 5(36):123-152.

[6] Malhotra Ak, Sharma AK. A study to assess, the disability impact on parents of children with mental retardation in two special schools of Delhi. Indian Journal. 2013; 44(1-2):25-27.

[7] Gohel S, Mukherjee SK, Choudhari M. Psychosocial impact on the parents of mentally retarded children in Anand District Manish. Health Line. 2011; 2(2):62-66.

[8] Richman NE, Corman H, Noonan K. Impact of child disability on the family. Maternal and Child Health Journal. 2007; 12(6):676-683. doi: 10.1007/s10995-007-0307-z

[9] Lazarus RS, Folkman S. Stress, appraisal and coping. New York: Springer; 1984.

[10] Åsberg KK, Vogel JJ, Bowers CA. Exploring correlates and predictors of stress in parents of children who are deaf: implications of perceived social support and mode of communication. Journal of Child and Family Studies. 2007; 17(4): 486-99. doi: 10.1007/s10826-007-9169-7

[11] Stora JB. Le stress [P. Dadsetan, Persian trans]. Tehran: Roshd publication; 2008.

[12] Brown G, Bramston P. Stress and the quality of life in the parents of young people with intellectual disabilities. Journal of Psychiatric Mental Health Nursing. 1998; 5(5):415-421. PMID: 10067490

[13] Singer GHS, Ethridge BL, Aldana SI. Primary and secondary effects of parenting and stress management interventions for parents of children with developmental disabilities: A meta-analysis. Mental Retardation and Developmental Disabilities Research Reviews. 2007; 13(4):357-369. doi: 10.1002/ mrdd.20175

[14] Amiri M, Afrooz GA, Malahmadi E, Javadi S, Nour-Allahi F, Rezaei-Bidakhavidi A. [A study of mental health and parenting stress among parents of mentally disabled children (Persian)]. Journal of Behavior Sciences. 2011; 4(4):261-268.

[15] McConkey R, Truesdale-Kennedy M, Chang M-Y, Jarrah S, Shukri R. The impact on mothers of bringing up a child with intellectual disabilities: A cross-cultural study. International Journal of Nursing Studies. 2008; 45(1):65-74. doi: 10.1016/j. ijnurstu.2006.08.007

[16] Osborne LA, Reed P. The Relationship between parenting stress and behavior problems of children with Autistic Spec- trum Disorders. Exceptional Children. 2009; 76(1):54-73. doi: 10.1177/001440290907600103

[17] Parish SL, Rose RA, Grinstein-Weiss M, Richman EL. Material hardship in U.S families raising children with disabilities. Journal of Exceptional Children. 2008; 75(1):71-92. doi: $10.1177 / 001440290807500104$

[18] Folkman S. Making the case for coping. In: Corpenter B, editor. Personal Coping; Theory, Research and Applications. New York: Praeger; 1992.

[19] Feher-Prout T. Stress and coping in families with deaf children. Journal of Deaf Studies and Deaf Education. 1996; 1(3):155-166. doi: 10.1093/oxfordjournals.deafed.a014291

[20] Janbozorgi M, Nouri N. [Stress and anxiety psychotherapy (Persian)]. Tehran: Samt Publication; 2010

[21] Hasanzadeh S. [Parenting stress in mothers with deaf children (Persian)]. Journal of Psychology and Education. 2012; 42(1):51-62.

[22] Meichenbaum D. Stress inoculation [S. Mobini, Persian trans]. Tehran: Roshd Publication; 1998

[23] Pourmohammadreza-Tajrishi M, Azadfallah P, Hemmati Garakani S, Bakhshi E. [The effect of problems-focused coping strategy training on psychological syndromes (Persian)]. Iranian Journal of Public Health. 2015; 44(2):254-262.

[24] Hossienkhanzadeh AA, Yeganeh T, Rashidi N, Zareimanesh G, Fayegi N. Effects of stress management training by using Cognitive-Behavioral method on reducing anxiety and depression among parents of children with mental retardation. Sociology Mind. 2013; 3(1):62-66. doi: 10.4236/ sm.2013.31011

[25] Rohini NS. Management of anxiety and QOL in the parents of children with special needs through positive therapy. International Journal of Multidisciplinary Research. 2012; 2(2):75-91.

[26] Raspa M, Bailey DB, Olmsted MG, Nelson R, Robinson N, Simpson ME, et al. Measuring family outcomes in early intervention: Findings from a large-scale assessment. Exceptional Children. 2010; 76(4):496-510. doi: 10.1177/001440291007600407

[27] Valizadeh Sh, Davoodifar A, Birdie Ozonye Doji R, Alayei Z. [Effectiveness skills training of coping on levels of stress and frustration mothers of mentally retarded children (Persian)]. Research on Exceptional Children. 2010; 3(10):237-244.

[28] Singer GH, Irvin LK, Hawkins N. Stress management training for parents if children with severe handicaps. Journal of Mental Retardation. 1988; 26(5):269-77.

[29] Kaveh M, Alizadeh H, Delavar A, Borjali A. [Development of a resilience fostering program against stress and its impact on quality of life components in parents of children with mild intellectual disability (Persian)]. Journal of Exceptional Children. 2011; 11(2):119-140.

[30] Yousofi-Naminy AS, Gobari-Bonab B, Hassanzadeh S, Sokoohi-Yekta M. Development of behavior management program for mothers of deaf children and studying its effectiveness on reduction of mothers stress. Journal of Clinical Psychology. 2014; 6(3):95-107 
